\title{
Functional single-nucleotide variant of HSPD1 in sudden infant death syndrome
}

\author{
Cornelius Courts ${ }^{1}$, Melanie Grabmüller ${ }^{1}$ and Burkhard Madea'
}

BACKGROUND: An insufficient stress response due to a genetically impaired heat shock protein ( $\mathrm{Hsp}$ ) could play a role in the pathogenesis in a subgroup of sudden infant death syndrome (SIDS) cases. Herein, we are the first to investigate whether a functionally impairing and thus pathogenic variant of the gene for Hsp60, encoded by HSPD1 (rs72466451), is correlated with the occurrence of SIDS.

METHODS: In a case-control study of a series of 133 cases of SIDS and 192 gender-matched German Caucasian control cases, the occurrence and distribution of the HSPD1 singlenucleotide variant (SNV) was analyzed using SNV genotyping by minisequencing.

RESULTS: The results show significantly increased frequency of the pathogenic variant of the HSPD1 SNV in a subgroup (4.5\%) of SIDS cases.

CONCLUSION: The results suggest that the pathogenic variant of rs 72466451 may play a role in a subgroup of SIDS cases with impaired Hsp60-mediated stress response.

$S^{n}$ udden infant death syndrome (SIDS) is defined as "the sudden unexpected death of an infant $<1 \mathrm{y}$ of age with onset of the fatal episode apparently occurring during sleep, that remains unexplained after a thorough investigation, including performance of a complete autopsy and review of the circumstances of death and the clinical history" and subcategorized by revised definition (1). Today, SIDS is still the major cause of death among infants between $1 \mathrm{mo}$ and $1 \mathrm{y}$ of age in developed countries $(2,3)$. SIDS is generally agreed to be a multifactorial disease and according to the frequently encountered "triplerisk hypothesis," SIDS may occur when an infant left vulnerable by a combination of predisposing and developmental risk factors encounters an environmental trigger event (e.g., sleeping in prone position, overheating) $(4,5)$. Predisposing risk factors include alterations in a plethora of genes, e.g., involved in thermoregulation and catecholamine production, as well as conditions such as abnormal brainstem processes in the regulation of autonomic respiration and/or arousal $(6,7)$.

Thermal stress, e.g., caused by slight infections, exaggerated room heating, or excessive insulation of the infant, is known to be a risk factor for SIDS (8-17), especially affecting infants with impaired thermal regulation. This is because there is a strong association between thermal regulation and ventilatory control, specifically for prolonged apnea $(18,19)$, which can be the proximate mechanism of death in SIDS. Thermal regulation is in part mediated by the thermal stress response, so it has been hypothesized that a deficient thermal stress response due to genetic alterations in the gene for heat shock protein 60 (Hsp60), encoded by HSPD1 (20), may play a role in the pathogenesis of a subgroup of SIDS cases (21).

However, to date only two studies investigated HSPD1 genetic alterations in SIDS and these brought forth contradictory results as to their potential impact: Rahim et al. analyzed an $M s p I$ restriction fragment length polymorphism in HSPD1 and reported one specific fragment to be significantly underrepresented in the SIDS group (22). The meaning of this study's findings is limited, however, by its small collective $(n=12)$ and its lack of correction for multiple testing in statistical analysis (23). Bross et al. investigated the distribution of several singlenucleotide polymorphisms in HSPD1 in a series of SIDS ( $n=$ 61 ) and control cases but in no instance could they establish a significant difference between SIDS and control cases (24). Moreover, both the studies focused on variants that had not previously been shown or suspected to be pathogenic by functionally impairing Hsp60.

This study is the first to examine in a substantially larger number of cases whether the nonsynonymous and known to be pathogenic (25) rare variant rs72466451 in the gene for Hsp60 is associated with the occurrence of SIDS.

\section{RESULTS}

\section{Distribution of HSPD1 SNV Allelic Variants}

Table 1 shows the results of the distribution analysis of the allelic variants of the HSPD1 SNV in controls and cases of SIDS. A significant association of the pathogenic "C" allele with SIDS was observed $(P=0.05)$.

The " $C$ " allele was unevenly, although not significantly differently, distributed between genders, with both control cases and five (of six) SIDS cases bearing a " $\mathrm{C}$ " allele being male (Table 2). Moreover, although there was an uneven distribution of "C" alleles between the age-grouped SIDS cases, with four (of six) "C" alleles found in SIDS cases in the risk age between 46 and $153 \mathrm{~d}$, there was no significant association $(P=0.532)$. 


\section{Distribution of HSPD1 SNV Genotype Variants}

Table 3 shows the results of the distribution analysis of the genotype variants of the HSPD1 SNV in controls and cases of SIDS. A significant association of the C/T genotype with SIDS was shown $(P=0.05)$.

However, the homozygous and pathogenic genotype $\mathrm{C} / \mathrm{C}$ was not detected at all, neither in control nor in SIDS cases. Therefore, the distribution of the heterozygous $\mathrm{C} / \mathrm{T}$ genotype equals the respective allelic distribution, with the $\mathrm{C} / \mathrm{T}$ genotype being more frequent in males and in SIDS cases in the risk age between 46 and $153 \mathrm{~d}$, although it was not significantly different in any of these instances (data not shown). Moreover, genotype distribution was calculated not to depart from Hardy-Weinberg equilibrium for SIDS and control cases (data not shown).

Table 1. Distribution of allelic variants of HSPD1 SNV

\begin{tabular}{lrrrrrrr} 
& \multicolumn{2}{c}{ SIDS cases } & & \multicolumn{2}{c}{ Controls } & \\
\cline { 2 - 3 } Allele & $n$ & $(\%)$ & & $n$ & $(\%)$ & Total \\
\hline T & 260 & 97.7 & & 382 & 99.5 & 666 \\
$\mathrm{C}$ & 6 & 2.3 & & 2 & 0.5 & 8 \\
Total $^{*}$ & 266 & 100 & & 384 & 100 & 674 \\
\hline
\end{tabular}

SIDS, sudden infant death syndrome; SNV, single-nucleotide variant. ${ }^{*} P=0.05$.

Table 2. Properties of SIDS and control cases bearing a pathogenic allele

\begin{tabular}{|c|c|c|c|c|c|c|}
\hline \multirow[b]{2}{*}{$\begin{array}{l}\text { Cause of } \\
\text { death }\end{array}$} & \multirow[b]{2}{*}{ Sex } & \multirow[b]{2}{*}{$\begin{array}{l}\text { Age of } \\
\text { death }\end{array}$} & \multicolumn{4}{|c|}{ Risk factors } \\
\hline & & & $\begin{array}{l}\text { Prone } \\
\text { position }\end{array}$ & $\begin{array}{c}\text { Light } \\
\text { infection }\end{array}$ & $\begin{array}{l}\text { Smoke } \\
\text { exposure }\end{array}$ & Overheating \\
\hline SIDS & M & $112 d$ & - & No & - & - \\
\hline SIDS & M & $168 d$ & No & No & - & - \\
\hline SIDS & M & $98 d$ & Yes & No & - & - \\
\hline SIDS & M & $56 d$ & No & No & - & - \\
\hline SIDS & M & $258 d$ & Yes & Yes & Yes & $p$ \\
\hline SIDS & $\mathrm{F}$ & $140 \mathrm{~d}$ & Yes & No & Yes & - \\
\hline $\begin{array}{l}\text { Polytrauma } \\
\text { (control) }\end{array}$ & $M$ & $5 y$ & $x$ & $x$ & $x$ & $x$ \\
\hline $\begin{array}{l}\text { ALD } \\
\text { (control) }\end{array}$ & M & $72 y$ & $x$ & $x$ & $x$ & $\mathrm{x}$ \\
\hline
\end{tabular}

Dashes in this table represent "unknown."

ALD, alcoholic liver disease; F, female; M, male; p, possibly; SIDS, sudden infant death syndrome; $x$, does not apply.

Table 3. Distribution of genotype variants of the HSPD1 SNV

\begin{tabular}{lccccccc}
\hline & \multicolumn{2}{c}{ SIDS cases } & & \multicolumn{2}{c}{ Controls } & \\
\cline { 2 - 3 } Alleles & $n$ & $(\%)$ & & $n$ & $(\%)$ & Total \\
\hline T/T & 127 & 95.5 & & 190 & 99.0 & 325 \\
T/C & 6 & 4.5 & & 2 & 1.0 & 8 \\
C/C & 0 & 0.0 & & 0 & 0.0 & 0 \\
Total $^{*}$ & 133 & 100 & & 192 & 100 & 333 \\
\hline
\end{tabular}

SIDS, sudden infant death syndrome; SNV, single-nucleotide variant. ${ }^{*} P=0.05$.

\section{DISCUSSION}

SIDS is most likely a complex and multifactorial disease. According to the "triple-risk hypothesis," contributing or predisposing factors are classified into genetic, developmental, and environmental factors ("triggers"). Therefore, each of a vast number of possible combinations of these factors could precipitate SIDS. However, with SIDS being a diagnosis of exclusion, it is important to keep in mind that no single factor, predisposing or else, can be determined that "causes" SIDS, because, per definition, SIDS is to be diagnosed only if no (other) cause can be determined (1). Therefore, many of the predisposing, i.e., genetic factors that have already been reported to be associated with the occurrence of SIDS (26-28) do not cause manifest disease that would thwart compatibility with a diagnosis of SIDS. Instead, they are thought to elicit or to be associated with only subtle changes in, e.g., biochemical, physiological, or immunological processes. These small alterations could then, if coalescing with a complementary instable developmental state and appropriate environmental conditions, provoke fatal crisis.

Many of these studies fail, however, to provide evidence that the genetic factors in question that had been associated with SIDS do have some, however small, effect. Hence, there is no shortage of reports acclaiming associations but providing only contrived hypotheses as to what these associations might actually mean.

The present study, therefore focuses on an SNV in the coding region of the gene for Hsp60, HSPD1, that creates a bona fide amino acid change in the protein and that has already been shown to cause manifest disease if present in a homozygous genotype (25). In addition, evidence for functional impairment of Hsp60 by this SNV has been produced by demonstrating reduced survival in transgenic Escherichia coli, especially when confronted with heat stress (25).

We hypothesize that homozygosity for this rare variant's pathogenic allelic variant, which notably was not observed in any single case in this study, probably causes a manifest, i.e., "stand-alone" disease that under particular circumstances might even be lethal in early phases of embryonic or fetal development and thereby precludes diagnosability of SIDS. If this hypothesis is true, it should also be investigated whether some deaths initially reported as SIDS were in fact due to a disease caused by a pathogenic homozygous genotype of the rs72466451 SNV.

Heterozygosity for this rare variant, however, is non-lethal, but the amino acid change it causes might create a somewhat impaired heat shock reaction by restricting the chaperonin's ability to bind or refold thermally deformed protein structures or to target them for degradation in the proteasome. This may cause an increased vulnerability to overheating that is not sufficient for symptomatic disease but is applicable to classify as a predisposing factor for SIDS that affects both genders alike. This hypothesis is corroborated by the fact that the pathogenic variant was also found in two controls who had not died of SIDS.

It follows from the above explicated interpretation of the "triple-risk hypothesis"- that is to say "many combinations of 
Table 4. Primers for HSPD1 locus amplification and SNV genotyping

\begin{tabular}{llcccc}
\hline Primer & Sequence $\left(5^{\prime} \rightarrow 3^{\prime}\right)$ & $\mathrm{GC}(\%)$ & $\mathrm{T}_{\mathrm{m}}\left({ }^{\circ} \mathrm{C}\right)$ & $\mathrm{C}_{\mathrm{f}}(\mu \mathrm{mol} / \mathrm{l})$ & Product length $(\mathrm{bp})$ \\
\hline HSPD1-f & CACAGTCTTTCGCCAGATGA & 50 & 58 & 0.5 & 139 \\
HSPD1-r & CACAGCATCGGCTAAAAGGT & 50 & 58 & 0.5 & 0.2 \\
HSPD1-SNPb & GGCATCTGCACCAAATTTTACA & 40.9 & 58 & 21
\end{tabular}

$C_{p}$ final concentration in PCR; GC, percentage of G and C nucleotides; SNP, single-nucleotide polymorphism; SNV, single-nucleotide variant; $T_{m^{\prime}}$, melting temperature.

ased for locus amplification. ${ }^{b}$ Used for SNV genotyping.

factors may lead to SIDS"-that certain combinations of complementary factors may have a higher plausibility of working together in causing SIDS. For instance, an infant with a genetic predisposition that impairs heat stress response might be more at risk when this predisposition is met with the "overheating" trigger. We propose that further studies of association take into account as far as possible potential reciprocity between the genetic factor in question and the actual trigger (e.g., prone position, overheating, slight infection) that was reported for each SIDS patient.

\section{Conclusions}

We observed a significant relationship between the genotype of a functional HSPD1 rare variant (rs72466451) and SIDS. This is the first study investigating the distribution of this pathogenic SNV in a SIDS case-control collective. Our results suggest considering a possible role of a genetically impaired heat shock reaction in the pathogenesis of a small subgroup of SIDS cases and should direct further work.

\section{METHODS}

\section{Patients and Diagnosis}

Our study collective consisted of 133 formalin-fixed, paraffinembedded samples of German Caucasian SIDS cases (82 males, 51 females, age of death 26-341 d, median 98 d) and 192 gendermatched control cases (120 males, 72 females). In all the cases, diagnosis of SIDS was according to the current definition (1) and based on a detailed and comprehensive postmortem investigation at the Institute of Legal Medicine (University of Bonn, Bonn, Germany). A total of $57.9 \%$ of SIDS patients were in the risk interval between 46 and $153 \mathrm{~d}$ postnatal upon death.

The German Caucasian controls consisted of biopsy material taken from the psoas major muscle during autopsy ( $n=154$; 94 males, 60 females, age of death 3-96 y, median 59 y) and voluntarily donated saliva samples from healthy subjects $(n=38$; 26 males, 12 females, aged 2-38 y, median 12 y). For deceased controls, diagnosis of SIDS was excluded. The study design provided for informed consent and was approved by the ethics committee of the medical faculty of the University of Bonn.

\section{DNA Extraction}

For SIDS cases, DNA was extracted from formalin-fixed paraffinembedded tissue using the QIAamp DNA FFPE Tissue Kit (Qiagen, Hilden, Germany). For control cases, the QIAamp DNA Investigator Kit (Qiagen) was used to extract DNA from saliva swabs and the Qiagen DNA Micro Kit (Qiagen) was used with tissue specimens. All kits were utilized according to the manufacturer's respective instructions. DNA concentration was determined fluorometrically using the Qubit fluorometer (Invitrogen/Life Technologies, Darmstadt, Germany) according to the supplied recommendations.

\section{Primer Design and PCR Amplification of HSPD1}

Amplification and typing primers were designed using the free online resource "Primer 3" (Whitehead Institute for Biomedical Research,
Cambridge, MA), checked for secondary structures and inter- and intracomplementarity using the "Netprimer" software (Premier Biosoft, Palo Alto, CA), and tested for specificity by performing a query using the Basic Local Alignment Search Tool ("BLAST", hosted online by the National Library of Medicine, Bethesda, MD). The primer details are listed in Table 4. The SNV in question, rs72466451, lies on chromosome 2 at position 198363487 (contig NT_005403.17) in exon 2 of HSPD1, and its G allele has been classified as "pathogenic." There are as yet no data concerning population diversity in regard to rs72466451 (29).

A $139 \mathrm{bp}$ stretch of the SNV-containing region was then amplified by PCR using the following cycling conditions: initial denaturation at $94{ }^{\circ} \mathrm{C}$ for $10 \mathrm{~min}$, denaturation at $94^{\circ} \mathrm{C}$ for $30 \mathrm{~s}$, annealing at $55^{\circ} \mathrm{C}$ for $30 \mathrm{~s}$, elongation at $72{ }^{\circ} \mathrm{C}$ for $30 \mathrm{~s}$, and final elongation at $72{ }^{\circ} \mathrm{C}$ for $5 \mathrm{~min}$, with 30 cycles. PCR was set up using standard conditions, with $1 \mathrm{ng}$ of DNA template and $1 \mathrm{U}$ of Taq-Polymerase (New England Biolabs, Ipswich, MA) used per reaction.

\section{Genotyping the HSPD1 Variant}

PCR products were cleaned up before sequencing using Exo-SAP-It (Affymetrix, Santa Clara, CA). Genotyping of the amplified SNV was then performed by minisequencing using the typing primer listed in Table 4 and the SNaPshot Multiplex System (Applied Biosystems/Life Technologies, Darmstadt, Germany) according to the manufacturer's instructions. Afterward, the products were treated with calf intestine phosphatase (Affymetrix) to eliminate interference with subsequent fluorescence detection. Sequence analysis could then be performed using a 310 Genetic Analyzer and GeneMapper software v.3.2 (Applied Biosystems/Life Technologies) according to the manual.

\section{Statistical Analysis}

The frequencies of the pathogenic allelic variants in the control group examined in this study were too small for a Pearson's $\chi^{2}$ test to be reliably performed. Therefore, Fisher's exact test was used instead; all $P$ values reported herein are one-sided and derived from it. Calculation of Fisher's exact tests, Bonferroni correction, and possible departure from Hardy-Weinberg equilibrium were performed using SPSS software v. 19 (SPSS, Chicago, IL).

\section{STATEMENT OF FINANCIAL SUPPORT}

No financial support was received for this study.

Disclosure: The authors report no financial ties or conflicts of interest.

\section{REFERENCES}

1. Krous HF, Beckwith JB, Byard RW, et al. Sudden infant death syndrome and unclassified sudden infant deaths: a definitional and diagnostic approach. Pediatrics 2004;114:234-8.

2. Mitchell EA. The changing epidemiology of SIDS following the national risk reduction campaigns. Pediatr Pulmonol Suppl 1997;16:117-9.

3. Nicholl JP, O'Cathain A. Epidemiology of babies dying at different ages from the sudden infant death syndrome. J Epidemiol Community Health 1989;43:133-9.

4. Byard RW, Krous HF. Sudden infant death syndrome: overview and update. Pediatr Dev Pathol 2003;6:112-27.

5. Filiano JJ, Kinney HC. A perspective on neuropathologic findings in victims of the sudden infant death syndrome: the triple-risk model. Biol Neonate 1994;65:194-7. 
6. Kinney HC, Richerson GB, Dymecki SM, Darnall RA, Nattie EE. The brainstem and serotonin in the sudden infant death syndrome. Annu Rev Pathol 2009;4:517-50.

7. Kinney HC. Brainstem mechanisms underlying the sudden infant death syndrome: evidence from human pathologic studies. Dev Psychobiol 2009;51:223-33.

8. Stanton AN. Sudden infant death. Overheating and cot death. Lancet 1984;2:1199-201.

9. Gilbert R, Rudd P, Berry PJ, et al. Combined effect of infection and heavy wrapping on the risk of sudden unexpected infant death. Arch Dis Child 1992;67:171-7.

10. Jackson JA, Petersen SA, Wailoo MP. Body temperature changes before minor illness in infants. Arch Dis Child 1994;71:80-3.

11. Jackson JA, Petersen SA, McKeever PA, Wailoo MP. Changes in deep body temperature before cot death. Arch Dis Child 1995;72:97.

12. Ponsonby AL, Dwyer T, Kasl SV, Cochrane JA. The Tasmanian SIDS CaseControl Study: univariable and multivariable risk factor analysis. Paediatr Perinat Epidemiol 1995;9:256-72.

13. Tuffnell CS, Petersen SA, Wailoo MP. Factors affecting rectal temperature in infancy. Arch Dis Child 1995;73:443-6.

14. Steinschneider A, Weinstein S. Sleep respiratory instability in term neonates under hyperthermic conditions: age, sex, type of feeding, and rapid eye movements. Pediatr Res 1983;17:35-41.

15. Nelson EA, Taylor BJ. Infant clothing, bedding and room heating in an area of high postneonatal mortality. Paediatr Perinat Epidemiol 1989;3:146-56.

16. Tuohy PG, Tuohy RJ. The overnight thermal environment of infants. N Z Med J 1990;103:36-8.

17. Williams SM, Taylor BJ, Mitchell EA. Sudden infant death syndrome: insulation from bedding and clothing and its effect modifiers. The National Cot Death Study Group. Int J Epidemiol 1996;25:366-75.
18. Bach V, Telliez F, Libert JP. The interaction between sleep and thermoregulation in adults and neonates. Sleep Med Rev 2002;6:481-92.

19. Guntheroth WG, Spiers PS. Thermal stress in sudden infant death: Is there an ambiguity with the rebreathing hypothesis? Pediatrics 2001;107:693-8.

20. Reading DS, Hallberg RL, Myers AM. Characterization of the yeast HSP60 gene coding for a mitochondrial assembly factor. Nature 1989;337:655-9.

21. Gozal D. Deficient heat shock protein expression: a potential mechanism for the sudden infant death syndrome. Med Hypotheses 1996;46:52-4.

22. Rahim RA, Boyd PA, Ainslie Patrick WJ, Burdon RH. Human heat shock protein gene polymorphisms and sudden infant death syndrome. Arch Dis Child 1996;75:451-2.

23. Tanner MS, Sharrard MJ, Rigby AS. Gene polymorphisms and the use of the bonferroni correction factor: when and when not to apply? Arch Dis Child 1997;76:386.

24. Bross P, Li Z, Hansen J, et al. Single-nucleotide variations in the genes encoding the mitochondrial Hsp60/Hsp10 chaperone system and their disease-causing potential. J Hum Genet 2007;52:56-65.

25. Magen D, Georgopoulos C, Bross P, et al. Mitochondrial hsp60 chaperonopathy causes an autosomal-recessive neurodegenerative disorder linked to brain hypomyelination and leukodystrophy. Am J Hum Genet 2008;83:30-42.

26. Weese-Mayer DE, Ackerman MJ, Marazita ML, Berry-Kravis EM. Sudden Infant Death Syndrome: review of implicated genetic factors. Am J Med Genet A 2007;143A:771-88.

27. Courts C, Madea B. Genetics of the sudden infant death syndrome. Forensic Sci Int 2010;203:25-33.

28. Opdal SH, Rognum TO. Gene variants predisposing to SIDS: current knowledge. Forensic Sci Med Pathol 2011;7:26-36.

29. National Center for Biotechnology Information, National Institutes of Health. dbSNP (Single Nucleotide Polymorphism Database), 2013. 